\title{
Riqueza, circulación de bienes y élites rurales en León en los siglos X y XI
}

Wealth, flow of goods and rural elites in León in 10th and 11th centuries

Analia Godoy

Universidad de Buenos Aires. CONICET.

Instituto de Historia Antigua y Medieval "Prof. José Luis Romero", Argentina

anaurgodoy@gmail.com

\section{Resumen:}

En el mundo medieval la riqueza era un medio para establecer y reforzar relaciones sociales expresadas como vínculos de amistad, fidelidad, dependencia. Este trabajo indaga los mecanismos a través de los cuales los propietarios acomodados, élites de las comunidades rurales leonesas, pusieron en circulación sus bienes más allá del intercambio mercantil. Se analiza, por una parte, el flujo de bienes en el interior de las comunidades rurales y, por otra parte, la entrega y la obtención de bienes de la aristocracia laica y eclesiástica. Se sostiene que en el siglo X, un momento de génesis de las relaciones feudales en la región, existió una intensa circulación de bienes en un sentido relativamente horizontal, puesto que los propietarios más ricos afianzaban su patrimonio y su preeminencia social a través de distintos préstamos y ayudas a campesinos en dificultades. Sin embargo, la extensión de los poderes señoriales desde mediados del siglo $\mathrm{X}$ habría desestructurado parcialmente esta dinámica social. Los distintos préstamos habrían servido a la extensión de relaciones de dependencia señorial a la vez que los propietarios locales ricos pudieron trazar relaciones más directas y provechosas con los poderes señoriales a través del intercambio de distintos bienes y servicios.

Palabras claVe: Élites rurales, Riqueza, Préstamos, Poderes señoriales .

\section{Abstract:}

In the medieval world wealth was a means to establish and reinforce social relationships that were presented as bonds of friendship, loyalty and dependency. This study examines how wealthy rural dwellers, the elites in rural communities flow their goods besides market exchange. To that end, it analyzes, on the one hand, the flow of goods within the rural community and on the other, gifts to or from lay and ecclesiastical aristocracies. It is suggested that in the tenth century, upon the onset of lay and monastic lordship in northern Iberia, there was a heavy horizontal flow of goods since wealthy rural dwellers consolidated their property and social standing by lending and helping peasants in need. However, the extension of lordship since late tenth century modified partially this social dynamics. Loans promoted peasant subjection and, in turn, wealthy rural dwellers were capable of establishing more direct and fruitful bonds with aristocracies through the exchange of goods and services.

KeYwORDs: Rural elites, Wealth, Loans, Lordship.

\section{INTRODUCCIÓN}

Desde las décadas centrales del siglo XX los historiadores han recurrido frecuentemente a los aportes de la antropología y sus análisis de sociedades "primitivas" contemporáneas para comprender la especificidad de los intercambios, la circulación de bienes y las concepciones de la riqueza en las sociedades precapitalistas. El clásico Essai sur le don de Marcel Mauss (1923) se tornó una referencia común al entender el don como acto social total, capaz de condensar instituciones económicas, políticas, religiosas y rituales, y como medio para establecer, mantener o reproducir relaciones sociales a partir de la obligación más o menos velada de la reciprocidad. Los estudiosos de la Edad Media han llamado la atención sobre las formas de intercambio de bienes que trascendían el mercado y el pago de rentas como, por ejemplo, la distribución del botín entre el jefe y sus guerreros (Bloch, 2016, p. 170; Duby, 1976, 1977). En el mismo sentido, el historiador ruso Aaron Gurievich (1990) indicaba que en la sociedad medieval la riqueza no era un fin en sí mismo, sino un medio para obtener y reforzar el poder social. La circulación de bienes contribuía a establecer y renovar los vínculos 
de parentesco, protección, dependencia y sumisión que expresaban relaciones sociales. Más importante que la riqueza era el significado que esta adquiría a través de su distribución, lo que se traducía en un código en el que la preeminencia de los señores era el resultado de su generosidad.

En el presente, tanto la especificidad de la concepción de la riqueza como las funciones y el significado de las prácticas de circulación y distribución de la misma en el mundo medieval siguen siendo objeto de discusión académica, como se manifestó en la celebración del coloquio de Bruselas del año 2008 consagrado a "Les élites et la richesse au Haut Moyen Agge" (Devroey, Feller, \& Le Jan, 2010). Los trabajos presentados insistían en la compleja relación entre poder y riqueza en la Edad Media. Si bien ambos elementos se solapaban, la riqueza no significaba mecánicamente poder, sino que debía atravesar una suerte de transformación para convertirse en el derecho de dominar y mandar; una conversión que la volviera socialmente aceptable a través de actos de generosidad, consumo suntuario o piadoso. Lejos de un capital a valorizarse, la riqueza en la sociedad medieval era atesorada, exhibida, consumida y puesta en movimiento para construir relaciones sociales que se expresaban como vínculos de amistad y de dependencia. Tomando como punto de partida y referencia obligada estas reflexiones, este trabajo indaga en las prácticas de distribución de distintos bienes a través de préstamos, entregas y donaciones por parte de los sectores destacados en los ámbitos rurales leoneses en los siglos X y XI, ${ }^{1}$ a los que la historiografía se ha referido recientemente como élites rurales (Aparisi Romero, 2013; Feller, 2003; Menant \& Jessenne, 2007).

\section{Circulación de bienes en las Comunidades ruRales: PrÉstamos, ayUda y PROTECCIÓN A CAMPESINOS EN DIFICULTADES}

Hacia el siglo $\mathrm{X}$ aparecen documentadas en la región leonesa un conjunto de comunidades rurales que constituirían los núcleos básicos de poblamiento campesino y de explotación productiva del espacio (Pallares $\&$ Portela, 2007). Por encima de estas, los centros urbanos, otros núcleos menores, como castros o castella, y los monasterios eran centros de organización de una territorialidad compleja y crecientemente jerarquizada a partir de la integración de los territorios al sur de la cordillera cantábrica en los marcos políticos monarquía astur (Martín Viso, 2002, pp.67-104,2016). Lejos de la homogeneidad, se encontrarían comunidades rurales de distinto tamaño, organización y grado de autonomía respecto de estos centros.

En cuanto a su estructura social, se trataba de comunidades internamente diferenciadas, lo que se expresaba a través de términos como los de "maiores" y "minores" y la referencia a los "boni homines" (Carvajal Castro, 2013; Luis Corral, 2015; Pastor, 1980, p. 37). Ciertamente, uno de los elementos que cimentaban esta diferenciación era la acumulación de un conjunto de bienes productivos -tierras, viñas, prados, derechos o partes de molinos, entre otros- en la misma villa o en villas cercanas, ${ }^{2}$ junto con la propiedad de medios técnicos adecuados, fundamentalmente animales de tiro (Clemente Ramos, 1989, p. 39). La adquisición de bienes rurales podía ir acompañada de otros mecanismos de afirmación de una posición social distinguida, como puede observarse en la trayectoria de los descendientes de Recaredo en Melgar de Foracasas. Iscam, a la vez que adquirió bienes en el entorno de Melgar, controlaba con sus hermanos, Tajón y Gómez, una iglesia rural, San Esteban de Boadilla de Rioseco, que donaron a San Clemente de Melgar. ${ }^{3}$ El control de tierras y de un centro de culto se combinó con una política matrimonial que permitió vincular a esta grupo con otras familias destacadas, a través del matrimonio de Ermildi, hermana de Iscam, con Saliti Álvarez, un importante propietario que contaba con numerosas extensiones de tierra, raciones en molinos y derechos de aprovechamiento de las aguas del Cea (Carvajal Castro, 2014, pp. 20-21).

El bienestar material de estos sectores, basado tanto en la extensión de sus explotaciones como en la posesión de medios técnicos, les permitía disponer de una producción excedentaria que podían destinar tanto al acrecentamiento de su patrimonio como al consumo de un conjunto de bienes cualitativamente distinto del común del campesinado y que podía incluir textiles finos, objetos de plata e incluso equipamiento militar, 
así como utensilios y prendas cuyo precio podía alcanzar el de una vaca o de un buey (Sánchez Albornoz, 1965, pp. 381-382). El principal medio a través del cual los propietarios rurales podían acceder a este tipo de bienes eran las transacciones con las aristocracias laicas y eclesiásticas (Davies, 2010, pp. 274-275). En efecto, las instituciones eclesiásticas y, a lo largo del siglo XI, también los magnates laicos, entregaban prendas tejidas, cobertores moriscos, objetos de plata y equipamiento para montar a cambio de los distintos espacios productivos adquiridos o como confirmación por las donaciones recibidas. El mencionado Saliti Álvarez obtuvo del monasterio de Cellariolo un silla y un freno para montar a caballo junto con tres sueldos de plata a cambio de la séptima parte del aprovechamiento del agua del Cea, mientras que Requisendo y Baltario recibieron como compensación por la donación hecha al monasterio de Ardón una colcha, un colchón de lana o de tela junto con un cobertor morisco y sacos, tal vez de cereales. ${ }^{4} \mathrm{Al}$ respecto, es necesario tener en cuenta las observaciones de Juan José Larrea (2013) acerca del papel de los bienes de prestigio en las áreas rurales en la Alta Edad Media como medios para asegurar y vehiculizar las transferencias de bienes en un contexto en el que difícilmente puede hablarse de un mercado de tierras. En efecto, la circulación de estos objetos pudo asegurar la extensión de los dominios aristocráticos a la vez que ciertamente visibilizaban las jerarquías sociales entre los propietarios rurales (Douglas \& Isherwood, 1996, pp. 36-47).

A los propósitos de este trabajo, interesa concentrarse en las prácticas a través de las cuales los propietarios acomodados dedicaron parte de su riqueza a afianzar una posición distinguida en el seno de la comunidad y reforzar su preeminencia social a través de distintos tipos de ayuda a campesinos en dificultades, entre los que pueden mencionarse los préstamos en especie, la protección y el cobijo, la ayuda en litigios judiciales o frente a sentencias cuyos costos no pudieran afrontarse, y la actuación como fiadores ante los poderes señoriales. En primer lugar, por la presencia en las fuentes y la atención que han merecido de los historiadores, se analizan los préstamos en especie -en particular, de cereales y vino-, llamados renovo, en los que las tierras y otros bienes agrarios eran tomados como prenda (Ladero Quesada, 1991, pp. 147-148). Se ha insistido, en general, en esta práctica como mecanismo de pauperización del campesinado y de acrecentamiento de los dominios señoriales, puesto que una vez adelantado el préstamo en especie, si los campesinos eran incapaces de satisfacerlo en un transcurso de tiempo, debían entregar sus tierras y perdían su carácter de propietarios (Sánchez Albornoz, 1978, pp. 41-42).

Sin negar este fenómeno, es interesante destacar que en los testimonios de los siglos X y XI se encuentran préstamos en especie que eran provistos por sectores no aristocráticos. Se trataría bien de propietarios rurales acomodados, bien de quienes ocupaban posiciones distinguidas, como los presbíteros. La primera situación es ilustrada por Arias y Flora cuyo dinamismo económico se evidenciaría en las tres compras de pequeños bienes rurales realizadas en un sitio mencionado como Villa de Meizara, en Fontecha, en el año 964 y que también figuran prestando cereales, queso y vino a Martín y Félix. ${ }^{5}$ En la segunda situación, puede mencionarse el caso del presbítero Braulio quien, además de adquirir tierras en Montecillo, prestó cereales a una viuda con sus hijos, y del presbítero Gutier, quien prestó “de renovo" cinco heminas de vino a Citi. ${ }^{6}$

La provisión de préstamos por propietarios rurales destacados ya ha sido observada por Luis García de Valdeavellano en su trabajo dedicado al renovo. Los distinguía del conjunto de los préstamos en especie puesto que se trataría de una ayuda económica "sin carácter usurario". Mientras que el resto de los préstamos de renovo eran definidos como préstamos usurarios a partir de cierta evidencia filológica que le permitía asimilar el vocablo renovo a la usura, la ausencia de esta voz en los diplomas referidos a quienes no pertenecerían a las aristocracias eliminaría el carácter usurario de los mismos (García de Valdeavellano, 1973, pp. 418-419, pp. 428-429). Este razonamiento, en el que el carácter usurario del préstamo provendría de la cuantía del interés y, por lo tanto, los préstamos al interior de la comunidad habrían sido menos onerosos para los campesinos, debe problematizarse.

En primer lugar, como ha sido señalado, el carácter usurario del préstamo no derivaría de la cuantía del interés sino que era la condición estructural del préstamo precapitalista, destinado a asegurar la subsistencia y el pago de la renta feudal (Colombo, 2015). ${ }^{7}$ En segundo lugar, resulta difícil saber en qué medida el 
precio de la tierra entregada respondía a las especies adelantadas y, por lo tanto, qué tan gravosos resultaban estos préstamos partiendo de una evidencia documental que no consigna el tamaño de los bienes donados o vendidos y en una economía en la que el precio no era expresión autónoma del valor sino que sobre este incidían un conjunto de elementos extraeconómicos. Un diploma refiere al "locro" por el préstamo de quince heminas de vino por las cuales, al cabo de seis años, debieron devolverse treinta sueldos, lo que no parece un "locro" desproporcionado teniendo en cuenta que doce años después otro diploma valoraba en cuarenta sueldos seis heminas de vino y tres modios de cereal. ${ }^{8}$

Los diplomas que recogen préstamos en especie tienden deliberadamente a ocultar la dimensión del lucro insistiendo en algunos casos en la igualdad y la equivalencia en la transacción, refiriendo un "pretium" absolutamente difuso ("Et accepimus de uos in pretio pro ipsa deuesa ipsa cibaria et ipsum kaseum et ipsum uinum quod debuimus nos a tibi Arias") o indicando solamente la idea de una compensación por el préstamo que no puede ser devuelto ("in orem pro ipsa ceuaria quem mizi prestatit"). ${ }^{9} \mathrm{Al}$ mismo tiempo, algunas compras y ventas por pequeñas cantidades de cereales o vino debían encubrir renovos no consignados como tales (Davies, 2007, pp. 156-160). ${ }^{10}$ Prohibido en la legislación eclesiástica, sancionado en la doctrina religiosa medieval pero moderado en la legislación de raíz visigoda, ${ }^{11}$ la opacidad que rodea el lucro de los préstamos en especie tal vez no obedeciera solamente a su problemática licitud, sino que se correspondiera con la posición y la estima de un conjunto de prestamistas que ocupaban posiciones destacadas en la sociedad medieval leonesa. El único caso que refiere la "usuram" se asocia al núcleo urbano de León, probablemente por un préstamo de dinero "ex peccunia" referido a un mercader. ${ }^{12}$

En tercer lugar, debe señalarse que algunos de los préstamos en especie asociados a sectores rurales destacados eran también referidos como "de renovo" por lo que no se comprobaría la ausencia definitiva del vocablo. ${ }^{13}$ Antes bien, la especificidad de estos préstamos no derivaría de su carácter más o menos gravoso -aspecto que resulta esquivo en la documentación disponible-, sino de su funcionamiento en un conjunto de prácticas mediante las cuales se tejían relaciones de ayuda al interior de la comunidad pero que, a la vez, acentuaban la desigualdad al reforzar la acumulación patrimonial en el vértice de la misma. ${ }^{14}$

Son significativos aquellos casos en los que los préstamos en especie aparecen relacionados con diplomas que refieren un sentido más amplio de protección y ayuda. Esta situación puede percibirse en los documentos que se refieren a Taurelo y Principia, una pareja de propietarios que adquirieron modestos bienes rurales hacia mediados de siglo X en el Valle de Ujo, en tierras asturianas. ${ }^{15}$ Las transferencias de bienes a esta pareja indican que su papel en la comunidad trascendía la mera acumulación. En efecto, Taurelo y Principia habían adelantado a Bonmenti (propietario en la Villa de Ujo) un carnero y un sueldo de sidra que este debía entregar a causa de un pleito por una vaca. Lejos de devolver estos u otros bienes inmediatamente, sus hijos retribuyeron el préstamo original después de la muerte de su padre, cuando necesitaron nuevamente la ayuda de la pareja. ${ }^{16}$ La relación, que incluyó al menos dos generaciones, permite intuir cierta estabilidad en las posiciones relativas de cada familia. A la vez, junto con estos préstamos se expresa un sentido de protección ligado al cuidado y a la provisión de ciertos bienes elementales, de lo que da cuenta la donación con la cual los benefició Recosinda porque le habían dado un cobertor y una sabana a la vez que la cuidaban, la abrigaban y le hacían mucho bien. ${ }^{17}$ En esta serie documental se observan propietarios cuyo ámbito de actuación no trascendía el espacio de una o varias villas muy próximas, capaces de acumular bienes rurales que no los alejaban definitivamente del nivel de vida del campesinado -como hubiera supuesto la propiedad única de iglesias, villas o molinos- pero les permitían una producción excedentaria, condición para prestar ayuda y protección a campesinos en dificultades materiales. ${ }^{18}$

En estas dificultades podrían distinguirse dos situaciones. Por una parte, en una economía campesina orientada fundamentalmente a la producción para el consumo, distintas circunstancias adversas (los "annus malus" a los que remiten ciertos diplomas) podrían traducirse en cosechas insuficientes para asegurar la supervivencia del grupo en aquellas unidades domésticas con escasa dotación de tierras o de mano de obra. ${ }^{19}$ 
En esos años difíciles debieron acudir a los préstamos en especie y, si bien es difícil profundizar en cada caso, se destaca la presencia de viudas con sus hijos y de hombres y mujeres solos, tal vez ancianos, entre los deudores documentados. ${ }^{20}$ Por otra parte, estas dificultades podrían derivar de sentencias judiciales en las que los culpables no podían afrontar las multas impuestas. En ambos casos, la ayuda trascendía el préstamo en sí mismo y apuntaba un sentido de protección general y de favor como el que podía implicar la acogida en una casa.

La ayuda podría no estar relacionada con la entrega de bienes sino con la comparecencia en un litigio, como la "adiutorium" que prestó el presbítero Melic al presbítero Nanino “in concilio" donde se seguiría un litigio contra él. ${ }^{21}$ En estas prácticas deben incluirse la actuación de los propietarios locales como fiadores de otros campesinos frente a los poderes señoriales. Fernando y Constancio se comprometieron bajo una fianza de cien sueldos a que Cidi Enecoz, Saboto, Matrebona y sus hijos no abandonasen Valdoré ni se acogiesen a un señor que no fuera Pedro Flaínez, y de manera similar Fernando Braóliz y Sabe Elías garantizaron que en el momento en el que conde Pedro Flaínez se presentase en su mandación, Juan y Gacilo le entregarían una villa y una heredad que debían como caloña. ${ }^{22}$ De la actuación de los vecinos como fiadores de otros miembros de la comunidad da cuenta un pergamino del siglo X que contiene dos documentos, por una parte, la donación a favor del obispo que fue obligado a realizar Revel, por otra parte, el compromiso de Godesteo y Durabiles, hombres de villa Mahudes al igual que Revel, de entregar cien sueldos en caso de que cualquier hombre sacara a Revel de la potestad del obispo de León. ${ }^{23}$

Estas prácticas permitieron a los propietarios acomodados no solo reforzar su acumulación patrimonial, sino afirmar su superioridad social frente al conjunto de la comunidad a través de la creación de vínculos de amistad y protección con quienes atravesaban distintas dificultades materiales y que pudieron dar lugar a relaciones de "patronazgo laxo" que no implicaban una relación de dependencia personal estrecha y definitiva. ${ }^{24} \mathrm{Al}$ igual que otros rituales como el consumo de pan y vino luego de la celebración de transacciones de compra y venta, estas prácticas significaban una parcial distribución de la riqueza entre los vecinos y podrían haber moderado la conflictividad generada por la desigualdad material. ${ }^{25} \mathrm{Si}$ bien reforzaban el poder de quien entregaba estos bienes, presentaban la desigualdad en términos parcialmente beneficiosos para la comunidad, estableciendo vínculos mutuos de solidaridad y obligación.

\section{Circulación de Bienes En un CONTEXTo SEÑORializado}

La integración de las comunidades rurales leonesas en las estructuras políticas del reino significó su progresiva subordinación a los magnates laicos y a las instituciones eclesiásticas que proyectaban su poder en la región, lo que modificaría su carácter y dinámica interna. Es lícito, entonces, analizar cómo se transformaron las prácticas hasta aquí estudiadas -que correspondían a un momento de formación y génesis de los poderes feudales - a partir de la plena consolidación de los mismos a lo largo del siglo XI.

En primer lugar, si bien se observa la continuidad de la práctica de los préstamos en especie (que todavía velan la dimensión del lucro insistiendo en las nociones de compensación por lo que no puede ser devuelto), ${ }^{26}$ se asiste a la disminución de las referencias en el registro diplomático a los préstamos por parte de propietarios locales como los observados en el apartado anterior. En efecto, dentro del margen de las colecciones documentales analizadas, pueden encontrarse en la segunda mitad del siglo X nueve documentos que refieren préstamos en especie, calificados o no como renovo, de los cuales cuatro corresponden a préstamos realizados por personas que no formarían parte de los grupos aristocráticos, mientras que solamente uno atañe a un magnate laico, uno a una institución religiosa, dos a un presbítero probablemente vinculado a la catedral leonesa y uno a un monje. ${ }^{27}$ Este patrón se modifica para el siglo siguiente, ya que de los nueve diplomas que refieren préstamos entre el año 1000 y el año 1049, solamente dos pueden ser asociados a sectores no aristocráticos. Esta tendencia se consolida en la segunda mitad del siglo XI, ya que en solamente 
uno de doce diplomas el préstamo no proviene de las aristocracias. ${ }^{28} \mathrm{La}$ ayuda material parece restringirse al seno de la comunidad doméstica, como el préstamo que hizo Elo a su comadre Velita de cinco cuartarios de cereales y dos sueldos de plata o la fianza que Vellite Eliániz dio por su hermana, ${ }^{29} \mathrm{o}$ bien tratarse de montos de menor cuantía no consignados por escrito.

Esta evolución puede responder solo parcialmente al sesgo crecientemente institucional de la documentación, ya que a lo largo del siglo XI los propietarios no aristocráticos no desaparecen definitivamente de los diplomas, si bien disminuye su visibilidad. En efecto, a lo largo del siglo las compras y permutas realizadas a nivel local por sectores no aristocráticos -tanto laicos como religiosos- se mantienen en un promedio cercano al $9 \%$ de la documentación total, si bien se observa una disminución respecto del número de diplomas que registran las adquisiciones por parte de magnates laicos y las donaciones a instituciones eclesiásticas. ${ }^{30}$ Puede tratarse de un indicio de cierta desestructuración de las dinámicas sociales en el interior de las comunidades rurales, que tendió a concentrar la provisión de préstamos en especie en los poderes aristocráticos y a relegar parcialmente el papel de los propietarios locales. Es interesante notar que la concentración de los préstamos de renovo por las aristocracias se manifiesta en el siglo X en zonas de más temprana señorialización, como Galicia (Isla Frez, 1992, p. 216).

Junto a la rarificación de los préstamos en especie, a lo largo del siglo XI tienden a desaparecer las menciones en la documentación a la actuación de propietarios locales como fiadores o personas capaces de adelantar las multas por sanciones judiciales. Esto se debería, en primer lugar, a que en el proceso de patrimonialización de la justicia en el norte de la península ibérica, los poderes señoriales se arrogaron el derecho de conmutar penas, sanciones y costas judiciales por distintos bienes agrarios de forma directa (Martínez Sopena, 2007, pp. 259-260). ${ }^{31}$ Pero, más interesante aún, en los casos en los que se encuentra algún tipo de mediación o préstamo para el pago de sanciones judiciales, este era provisto por otros aristócratas. Un caso de sumo interés puede mencionarse. Vistremiro, quien se había involucrado con la mujer de otro hombre, fue encarcelado en 1030 por Annaya Velázquez, imponiéndosele el pago de trescientos sueldos para reparar los daños. Sin tener cómo afrontar la sanción, Vistremiro escapó y, al ser capturado nuevamente, los monjes del monasterio de Sahagún "pactaron" por él entregando a Annaya un caballo valorado en doscientos sueldos. Por este motivo Vistremiro y su mujer donaron al monasterio su heredad en San Andrés, en Grajal. ${ }^{32}$ El desplazamiento de los actores que proveían los préstamos para afrontar la sanción transforma el sentido de la práctica, puesto que la ayuda y la posterior donación ya no reforzaban una preeminencia laxa sobre la comunidad, sino que contribuían a crear o asegurar vínculos de dependencia señorial. En efecto, cuando hacia finales de siglo XI Annaya Pérez y sus hijos no pudieron cumplir con los cien sueldos que debían "in manfecta" a Pelayo Muñoz, la suma fue entregada por los monjes de Sahagún, a cambio de lo cual Annaya y sus hermanos donaron tres solares que conservarían para servir al monasterio. ${ }^{33}$

En términos similares se transformaría la práctica de la provisión de fianzas, como permite atisbar el caso de Adulfo hacia mediados del siglo XI. Adulfo había abandonado a su mujer y fue obligado a volver con ella, siendo fiador por el cumplimiento de la sentencia el presbítero Pedro, quien sería responsable de asegurar el pago de veinte sueldos en el caso de que el hombre dejara nuevamente a su esposa. Adulfo incumplió el mandato y no pudiendo pagar los veinte sueldos, fue obligado a prestar servicio en un solar de la reina. En esta nueva sentencia el fiador no sería ya un presbítero ni un miembro destacado de la comunidad sino un magnate laico, Justo Señórez, quien se comprometió a que Adulfo realizara el servicio ("et dedit fidiatore Iusti Sennorez ad illa regina pro ipso labore que fecit in ipso solare de illa regina illo Adulfo"). ${ }^{34}$ Si la práctica de los préstamos o de las fianzas no parece modificarse formalmente, su contenido se transformaba en el sentido de una mayor subordinación del campesinado respecto de los poderes señoriales.

En adelante, los miembros destacados de las comunidades acompañarían a otros campesinos en los juicios e intercederían frente a los poderes señoriales, lo que se manifiesta en aquellos diplomas que refieren la actuación de los “boni homines" en el ámbito judicial (Davies, 2016, pp. 169-176; Luis Corral, 2015). Se 
ha estudiado en particular práctica del "rocum" (ruego) y "atiba", como forma de llegar a acuerdos que suponían una reducción de las penas impuestas (Martínez Sopena, 2007). En estos casos, no se adelantaban bienes sino que los hombres confiables y de buena reputación comparecían junto a los campesinos ante los jueces y hablaban por ellos frente a los señores ("ut fabulassent pro me"), expresando en el plano simbólico la desigualdad. ${ }^{35}$

La disminución en la documentación de las menciones de transferencia de bienes al interior de las comunidades rurales tiene como contrapartida el incremento de la circulación de bienes entre los propietarios rurales y las aristocracias: en particular, las donaciones para asegurar la protección de los señores y las concesiones de bienes en benefactoría.

Frente a la extensión de las esferas de poder señorial, algunos campesinos habrían entregado distintos bienes agrarios para entrar en la protección de un magnate o de una institución eclesiástica, escapando así de servicios en trabajo o de formas de dependencia más onerosas. Esto es lo que parece indicar la donación de Cide Albónez, quien en el año 1027 entregó un linar y la séptima parte de un prado al conde Pedro Fernández porque lo había liberado de una "mala autoridad" y le había hecho "bien". ${ }^{36}$ Este fenómeno se expresa de manera más sugerente aún en la donación que hizo Diego Pátrez de un solar al monasterio de Sahagún para estar "libre durante toda su vida de todo servicio humano", estableciendo además que después de su muerte sus hijos no estuvieran "sometidos tan estrictamente en el servicio" como otros, sino que sirviesen solamente doce días por año y, si tuvieran caballos, se les permitiera "servir como caballeros" ${ }^{37}$ Además de advertir la labilidad, aún hacia finales del siglo XI, de la barrera social que separaba a campesinos de caballeros, este documento sugiere cierta capacidad de negociación de los estratos campesinos, para los cuales la transferencia de bienes a las aristocracias sería una de las formas posibles de escapar de una dependencia más severa.

También se observa cierta capacidad de negociación asociada a la posibilidad de elegir señor al cual acogerse, lo que aparece estrechamente vinculado a las entregas de bienes en benefactoría. Se trataba de un tipo de donación mediante la cual los magnates laicos buscaron asegurarse la prestación de distintos servicios de quienes puede suponerse sectores rurales acomodados y a las que remiten una veintena de diplomas entre finales del siglo X y comienzos del siglo XII. ${ }^{38}$ El mencionado Diego Pátrez obtuvo el solar donado de Tello Gutiérrez por su buen servicio y, si bien durante la vida de Tello y de su hermana Velasquita había estado obligado a servirlos, después de su muerte quedó autorizado a elegir señor libremente ("cum domno qui tibi bene placuerit iure libero"), lo que efectivamente hizo. ${ }^{39}$

Este tipo de pactos ha sido interpretado de distintas formas: como relaciones de encomendación de campesinos libres que requerían protección respecto de patrones aristocráticos (Sánchez Albornoz, 1965, pp. 107-109), como tipo de relación señorial cuya única excepcionalidad consistía en la capacidad de elegir señor (Martínez Sopena, 1985, pp. 238-239), como concesiones a campesinos enriquecidos, boni homines o milites de la comunidad de aldea sujetos a relaciones de dependencia personal respecto de la aristocracia magnaticia (Estepa Díez, 2003, pp. 45-47, 2007), como pactos privados de protección por servicios que vinculaban desde la aristocracia hasta los campesinos solariegos (Martínez García, 2010) o como prácticas derivadas de sociedades campesinas progresivamente subsumidas a la lógica feudal (da Graca, 2011). A la vez, la perdurable asociación en la historiografía entre la benefactoría de los siglos X y XI y los señoríos de behetría de siglos posteriores ha condicionado cierta tendencia a analizar todas las dotaciones de tierra a cambio de servicios como prolegómenos de situaciones de dependencia señorial asociados a las prestaciones en trabajo. Sin embargo, las dotaciones no significaron siempre mecanismos destinados a la extracción del excedente agrario, sino que, como se analiza a continuación, implicaron en ciertos en casos formas de promoción social para quienes eran dotados.

Debe señalarse, en primer lugar, que la noción de "buen servicio" que aparece en los diplomas como motivo de las dotaciones de tierras por parte de los magnates laicos no puede asimilarse sin más a la realización de tareas productivas. En efecto, aquellos documentos que implican servicios agrarios suelen referirlos a través 
de la necesidad, expresada en alguna forma del presente o del futuro, de que el campesino sirva con un determinado bien como condición para conservar su tenencia ("et faciat seruitium cum illa", "faciant cum ea seruicio") o como premisa para ser dotado, tal como refiere la donación que hizo Adosinda Gutiérrez a Munio Cítiz de la mitad de un solar con sus bienes anexos para que "me sirvas con este durante mi vida" ${ }^{40} \mathrm{~A}$ diferencia de estos, las dotaciones por el "buen servicio", suelen ser expresadas en un pretérito que se acerca a la noción de un servicio recompensado a través de la entrega de bienes y que se aspira a conservar en el futuro ("propter seruitium bonum quod fecit nobis" o "quod michi fecisti" "servitios bonos que nobis fecisti et promitis facere"). ${ }^{41}$

Otros indicios permiten sostener la interpretación que aleja el "buen servicio" del trabajo agrario y lo acerca a servicios de tipo militar. Por una parte, como ha sido señalado, la presencia predominante de caballos de gran valor, sillas de montar, espadas y galgos entre los bienes que los beneficiarios entregan a sus benefactores indica que compartían con estos los signos de una identidad guerrera (da Graca, 2011, pp. 28-29). ${ }^{42}$ Los diplomas que ofrecen más información que el mero "buen servicio" refuerzan esta percepción. En el año 1042 Munio Alfonso entregó a Diego González la mitad de una villa en su población en Villa Vega por el buen servicio que siempre le había prestado y porque "saliste conmigo de mi tierra" ${ }^{43}$ Parece indicarse que el mencionado Diego González siguió a Munio Alfonso en su exilio, situado por Martínez Sopena (1987, p. 37) entre los años 1036 y 1038 cuando, abandonando presuntamente el séquito de Vermudo III de León, Munio se habría dirigido a Castilla alineándose detrás del victorioso Fernando I. Así también, cuando en el año 1073 Juan Vermúdez entregó a Domingo Álvarez un solar por el buen servicio que le había prestado, agregaba también un potro para que "me sirvas en este". ${ }^{44}$ Servicios de vigilancia, de compañía armada y concurrencia a asambleas -que se manifiestan en la aparición como confirmantes junto con el donante en distintos diplomas ,$-{ }^{45}$ indican una relación de fidelidad ligada a la prestación de servicios especializados antes que a la sujeción y el trabajo en la tierra.

Estos diplomas remiten a dotaciones de tierras y concesiones en beneficio mediante los cuales los señores retribuían a sus vasallos y clientelas armadas en el proceso de estructuración de las relaciones feudales. La historiografía ha indicado la integración en estas relaciones de grupos de origen campesino alejados progresivamente de las actividades productivas (Astarita, 2007; Beceiro Pita, 1998; Bonnassie, 1988; Larrea Conde, 2002; Pastor, 1999; Pescador, 1961; Salrach, 1998). La presencia de propietarios acomodados entre quienes eran dotados por sus buenos servicios puede deducirse de los bienes que se entregaban en contraprestación. Como se dijo, entre las retribuciones más extendidas se encuentran los caballos de gran valor, metálico - veinte, treinta o cincuenta sueldos de plata- y otros bienes apreciados que indicarían el nivel de bienestar material de quienes fueron beneficiarios de estas concesiones. ${ }^{46}$ Asimismo, estos documentos dan cuenta del acceso a un conjunto de objetos asociados a pautas de consumo y prácticas eminentemente aristocráticas. Cuando Domingo Élaz recibió una tierra por el buen servicio prestado, entregó para roborar el documento un paño "canzi”, presuntamente proveniente del norte de África, y Pelayo Antóniz, al recibir cinco partes en Villacreces dio en confirmación un azor, un ave asociada a la cetrería. ${ }^{47}$ En estos casos, los caballos, las telas finas, las aves de caza entregados a las aristocracias servían tanto a la construcción y el reforzamiento de relaciones de amistad y de poder como a la materialización del status y la posición distinguida de estos sectores. La posesión y la puesta en circulación de ciertos bienes “de prestigio" previene, asimismo, de asociar sin más el consumo de los mismos a las aristocracias, una cuestión que está siendo problematizada por la arqueología medieval. ${ }^{48}$

Se trataría, entonces, de donaciones que vinculaban a las élites rurales con la aristocracia magnaticia en virtud de la prestación de un conjunto de servicios que podrían incluir una variedad de funciones militares y de compañía y que remiten a un tipo de servicio honorable y no degradante. La propia imprecisión que lleva implícita la noción de "buen servicio" ha sido vista, además, como evidencia de servicios que no pueden ser estimados en un precio y por lo tanto no degradan a quienes los prestan ni a quienes los retribuyen (White, 
2003, p. 79). El intercambio de bienes entre el donante que entregaba la tierra y el beneficiario que concedía a su vez alguno de los objetos mencionados sellaba el pacto de protección y "bene facere" entre ambos. En tal sentido, si muchos de los bienes dados en contrapartida aparecen con una estimación de su valor no se trataba de una compensación por la tierra, el solar o la villa que se estaba recibiendo sino un presente "in meo honore" que venía a confirmar la donación, exponiendo la perdurable necesidad de la puesta en circulación de la riqueza para afianzar las relaciones sociales de dominio y protección. La relación no se agotaba en el intercambio del "buen servicio" por los bienes dados en benefactoría sino que los caballos, los tejidos, los azores o el metálico ponían en marcha nuevamente la circulación reforzando las obligaciones mutuas.

\section{REFLEXiones FinALES}

En la introducción a "Negotiating the Gift: Pre-Modern Figurations of Exchange", Gadi Algazi (2003) señalaba las dificultades que encontraba la aplicación mecánica del modelo de Mauss al estudio de la Edad Media y proponía hablar de las cosas que se hacian con los dones ("doing things with gifts"). En tal sentido, se ha mostrado qué pudieron hacer los sectores rurales más prósperos con su riqueza más allá del acrecentamiento de su patrimonio, enfatizando particularmente la capacidad de esa riqueza para articular diversos vínculos sociales. De esta forma se identificaron dos circuitos diferenciados de circulación de los bienes, con lógicas particulares. Por una parte, un movimiento relativamente horizontal -evidenciado en préstamos y ayudas a campesinos en dificultades materiales- que, si bien no daba lugar a relaciones de dependencia señorial, reforzaba una posición social preeminente no agotada en lo material. Por otra parte, un movimiento vertical de bienes y servicios - manifestado en la entregas de bienes en benefactoría y la prestación del "buen servicio"que les permitió establecer o renovar vínculos sociales con las aristocracias a través de los que pudieron acrecentar su patrimonio, escapar de formas de dependencia más severas o consolidar una posición social distinta del resto del campesinado.

Si bien ambos circuitos coexistieron en el período estudiado, la presencia en la documentación diplomática de uno y otro presenta variaciones sugestivas: a lo largo del siglo XI se van reduciendo las menciones a intercambios de bienes entre campesinos a la vez que se incrementan las que refieren intercambios con las aristocracias magnaticias y eclesiásticas. Los cambios en las formas y en el sentido de la circulación de bienes y servicios pueden interpretarse a partir de la transformaciones sociales que se produjeron en este período. La consolidación de las aristocracias y la extensión de los poderes señoriales sobre las comunidades rurales transformaron ciertas dinámicas sociales, condicionando la reproducción de las élites rurales como tales. Por una parte, la capacidad de las aristocracias de conmutar directamente las penas por bienes agrarios y su mayor presencia como proveedoras de préstamos en especie desplazaron a los sectores más prósperos de su papel como respaldo material de sus vecinos. Por otra parte, se abrieron para estos nuevos mecanismos de encumbramiento y promoción social ligadas al intercambio de bienes con las aristocracias, como la aceptación de bienes en benefactoría. Lejos de una economía del regalo en la que el intercambio de dones reproduce las mismas relaciones sociales, en un período de cambio estructural, se vieron alteradas las formas de circulación de bienes así como el significado que estos adquirían. Qué hacían los miembros destacados y los propietarios más prósperos de las comunidades rurales de la región leonesa cuando prestaban o donaban sus bienes y qué tipo de vínculos buscaron crear o fortalecer debe entenderse necesariamente en relación con el desarrollo feudal y la consecuente transformación en el carácter y la posición de estos grupos.

\section{Colecciones documentales}

Fernández Flórez, J. A., y Herrero de la Fuente, M. (1999). Colección documental del monasterio de Santa Maria de Otero de las Dueñas I (854-1108). León: Centro de Estudios e Investigación "San Isidoro". 
Herrero de la Fuente, M. (1988). Colección diplomática del monasterio de Sahagún (857-1230), Vol. II (1000-1073). León: Centro de Estudios e Investigación “San Isidoro”.

Mínguez Fernández, J. M. (1976). Colección Diplomática del monasterio de Sahagún (Siglos IX y X). León: Centro de Estudios e Investigación "San Isidoro".

Ruiz Asencio, J. M. (1990). Colección Documental del Archivo de la Catedral de León (775-1230), Vol. IV (1032-1109). León: Centro de Estudios e Investigación "San Isidoro".

Ruiz Asencio, J. M. (1990). Colección Documental del Archivo de la Catedral de León (775-1230). Vol. III (986-1031). León: Centro de Estudios e Investigación "San Isidoro".

Ruiz Asencio, J. M., Ruiz Albi, I., y Herrero Jiménez, M. (2010). Los becerros gótico y galicano de Valpuesta. Madrid y Burgos: Real Academia Española, Instituto Castellano y Leonés de la Lengua.

Ruiz Asencio, J. M., y Ruiz Albi, I. (2007). Colección documental del monasterio de San Pedro de Eslonza, I, (912-1300). León: Centro de Estudios e Investigación "San Isidoro".

Sáez, E, y Sáez, C. (1987). Colección Documental del Archivo de la Catedral de León (775-1230). Vol. II (953-985), Centro de Estudios e Investigación “San Isidoro”.

Sáez, E. (1987). Colección Documental del Archivo de la Catedral de León (775- 1230). Vol. I (775-952). León: Centro de Estudios e Investigación "San Isidoro”.

\section{REFERENCIAS}

Algazi, G. (2003). Doing things with gifts. En G. Algazi, V. Groebner, \& B. Jussen (Eds.), Negotiating the Giftz: PreModern Figurations of Exchange (pp. 9-29). Göttingen: Vandenhoeck \& Ruprecht.

Aparisi Romero, F. (2013). Las élites rurales en la Edad Media como objeto de estudio: de la marginalidad al centro del debate historiográfico. Historia. Instituciones. Documentos, 40, 11-34. Recuperado de http://dx.doi.org/10. 12795/hid.2013.i40.01.

Astarita, C. (2007). Sobre los orígenes de las caballerías en Castilla y León . Siglos X-XII. Olivar, 8(10), 279-312.

Barbero, A., \& Vigil, M. (1978). La formación del feudalismo en la Peninsula Ibérica. Barcelona: Crítica.

Beceiro Pita, I. (1998). Criados, oficiales y clientelas señoriales en Castilla (siglos XI-XV). Cuadernos de historia de España, 75, 59-84.

Bloch, M. (2016). La sociedad feudal. Buenos Aires: Claridad. Primera edición 1939-1940.

Bonnassie, P. (1988). Cataluña mil años atrás (Siglos X-XI). Barcelona: Ediciones Península.

Bourin, M. (2007). Peasant Elites and Village Communities in the South of France, 1200 1350. Past \& Present, 195(2), 101-114. Recuperado de https://doi.org/10.1093/pastj/gtm024

Carvajal Castro, Á. (2013). Sociedad y territorio en el norte de León: Valdoré, los Flaínez y el entorno del alto Esla (siglos IX-XI). Studia Historica. Historia Medieval, 31, 105-131.

Carvajal Castro, Á. (2014). Los castros de la meseta del Duero y la construcción de la monarquía asturleonesa: el caso de Melgar en el siglo X. En A. Cunha, O. Pinto, \& R. de Oliveira Martins (Eds.), Paisagens e Poderes no Medievo Ibérico Actas do I Encontro Ibérico de Jovens Investigadores em Estudos Medievais - Arqueologia, História e Património (pp. 11-29). Braga: Centro de Investigação Transdisciplinar «Cultura, Espaço e Memória» Universidade do Minho.

Clemente Ramos, J. (1989). La estratificación económica del campesinado septentrional castellano-leonés (siglos XIXIII). Alcántara. Revista del seminario de estudios cacereños (16), 35-62.

Colombo, O. (2015). ¿Por qué el campesino se endeuda?: El significado de la usura medieval (Castilla, s. XV). Sociedades Precapitalistas, 5(1).

da Graca, L. (2011). Prácticas campesinas en un contexto feudalizado: las relaciones de benefactoría (siglos XI y XII). En la España Medieval, 34, 25-60. https://doi.org/10.5209/rev_ELEM.2011.v34.36293

Davies, W. (2007). Acts of giving. Individual, community, and Church in Tenth-Century Christian Spain. Oxford, New York: Oxford University Press. 
Davies, W. (2010). Notions of wealth in the charters of ninth- and tenth-century Christian Iberia. En R. Le Jan, L. Feller, \& J.-P. Devroey (Eds.), Les élites et la richesse au Haut Moyen Agge (pp. 265-284). Turnhout: Brepols.

Davies, W. (2016). Windows on Justice in Northern Iberia 800-1000. London, New York: Routledge.

Devroey, J.-P., Feller, L., \& Le Jan, R. (2010). Les élites et la richesse au Haut Moyen Âge. Turnhout: Brepols.

Douglas, M., \& Isherwood, B. (1996). The World of Goods. Towards an anthropology of consumption. Londres, Nueva York: Routledge.

Duby, G. (1976). Guerreros y campesinos. Desarrollo inicial de la economia europea, 500-1200. México: Siglo XXI.

Duby, G. (1977). Los «jóvenes» en la sociedad aristocrática de la Francia del Noroeste en el siglo XII. En Hombres y estructuras de la Edad Media (pp. 132-147). México: Siglo XXI.

Estepa Díez, C. (2003). Las behetrías castellanas (Vol. 1). Valladolid: Junta de Castilla y León.

Estepa Díez, C. (2007). Hombres de benefactoría y behetrías en León (siglos XI-XIV). Aproximación a su estudio. En A. Rodríguez (Ed.), El lugar del campesino: en torno a la obra de Reyna Pastor (pp. 113-139). València: PUV.

Feller, L. (2003). L'historiographie des élites rurales dans le Haut Moyen Âge. Emergence d'un problème? En $L$ 'historiographie des élites dans le Haut Moyen Agge. Marne-la-Vallée, France. Recuperado de https://halshs.arch ives-ouvertes.fr/halshs-01280002/document

Feller, L. (2015). Campesinos y señores en la Edad Media. Siglos VIII-XV. Valencia: PUV.

García Arias, X. L. (2006). Arabismos nel dominiu llingüisticu ástur. Oviedo: Academia de la Llingua Asturiana.

García de Valdeavellano, L. (1973). El «renovo». Notas y documentos sobre los préstamos usurarios en el Reino asturleonés (siglos X-XI). Cuadernos de Historia de España, LVII-LVII, 408-448.

Gautier Dalché, J. (1997). Du royaume asturo-léonais à la monarchie castillano-léonaise: Une histoire monétaire singulière (VIIIe-IXe siècle). En L'argent au Moyen Âge. Actes des congrès de la Société des historiens médiévistes de l'enseignement supérieur public, 28 e congrès, Clermont-Ferrand, 1997 (pp. 77-92). Paris: Publications de la Sorbonne. Recuperado de https://doi.org/10.3406/shmes.1997.1718

Gurievich, A. (1990). Las categorías de la cultura medieval. Madrid: Taurus.

Hautefeuille, F. (2007). Les élites rurales laissent-elles une trace archéologique? Étude à partir de quelques cas du sud-ouest de la France. En F. Menant \& J.-P. Jessene (Eds.), Les Elites rurales dans l' Europe médiévale et moderne. Actes des XXVIIes Journeés Internationales d'Histoire de l'Abbaye de Flaran 9, 10, 11 septembre 2005 (pp. 163-178). Toulousse: Universitaires du Mirail.

Isla Frez, A. (1992). La sociedad gallega en la Alta Edad Media. Madrid: CSIC.

Jiménez Muñoz, F. J. (2008). El tratamiento de los intereses en el derecho canónico y en el derecho islámico. RDUNED. Revista de derecho UNED, 3, 71-100.

Kjær, L., \& Waston, A. J. (2011). Feasts and gifts: sharing food in the middle ages. Journal of Medieval History, 37, 1-5. Recuperado de https://doi.org/10.1016/j.jmedhist.2010.12.005

Ladero Quesada, M. A. (1991). Crédito y comercio de dinero en la Castilla medieval. Acta historica et archaeologica mediaevalia, 11-12, 145-159.

Larrea Conde, J. J. (2002). La infanzonía en una perspectiva comparada: infanzones y arimanni del ordenamiento público al feudal. En P. Bonnassie, H. Débax, \& B. Cursente (Eds.), Fiefs et féodalité dans l'Europe méridionale (Italie, France du Midi, Péninsule ibérique) du Xe au XIIIe siècle. Colloque international organisé par le Centre Européen d'art et civilisation médiévale de Conques et l'Université de Toulouse-Le Mirail, Conques, 6-8 juillet 1998 (pp. 363-393). Toulousse: CNRS, Université de Toulouse-Le Mirail.

Larrea, J. J. (2013). Du Tiraz de Cordoue aux montagnes du Nord Le luxe en milieu rural dans l'Espagne chrétienne du haut Moyen Âge. En L. Feller \& A. M. Rodriguez López (Eds.), Objets sous contraintes. Circulation des richesses et valeur des choses (pp. 43-62). Paris: Publications de la Sorbonne.

Loveluck, C. (2009). The dynamics of elite lifestyles in the «rural world», AD 600-1150: archaeological perspectives from northwest Europe, 149-170. En F. Bougard, R. Le Jan \& R. McKitterick (Eds.), La culture du Haut Moyen Âge: une question d'élites? (pp. 139-170). Turnhout: Brepols. 
Luis Corral, F. (2015). Lugares de reunión, boni homines y presbíteros en Valdevimbre y Ardón en la Alta Edad Media. Medievalista [online] (18). Recuperado de http://www2.fcsh.unl.pt/iem/medievalista/MEDIEVALISTA18/c orral1805.html

Marlasca Rodríguez, O. (2008). El préstamo de géneros en la sociedad romana, visigoda y en algunos reinos cristianos de la Alta Edad Media. Anuario da Facultade de Dereito da Universidade da Coruña, 12, 599-613.

Martín Viso, I. (2002). Fragmentos del Leviatán. La articulación politica del espacio zamorano en la Alta Edad Media. Zamora: Instituto de Estudios Zamoranos «Florián de Ocampo».

Martín Viso, I. (2016). Colapso político y sociedades locales: el noroeste de la península ibérica (siglos VIII-IX). Reti Medievali Rivista, 17(2), 334-369. Recuperado de http://dx.doi.org/10.6092/1593-2214/523

Martínez García, L. (2010). Los pactos de benefactoría en la formación de la red feudal leonesa y castellana (siglos XXII). Hispania, 70(235), 325-357.

Martínez Sopena, P. (1985). La tierra de Campos occidental: poblamiento, poder y comunidad del siglo X al XIII. Valladolid: Institución Cultural Simancas.

Martínez Sopena, P. (1987). Parentesco y poder en León durante el siglo XI. La «casata» de Alfonso Díaz. Studia Historica. Historia Medieval, 5, 33-88.

Martínez Sopena, P. (2007). La justicia en la época asturleonesa: entre el Liber y los mediadores sociales. En A. Rodríguez (Ed.), El lugar del campesino: en torno a la obra de Reyna Pastor (pp. 239-260). Valencia: PUV.

Mauss, M. (1923). Essai sur le don. Forme et raison de l'échange dans les sociétés primitives. l'Année Sociologique, (Seconde série), 30-186.

Menant, F., \& Jessenne, J.-P. (2007). Introduction. En F. Menant \& J.-P. Jessenne (Eds.), Les Élites rurales dans $l$ 'Europe médiévale et moderne. Actes des XXVIIes Journées Internationales d'Histoire de l'Abbaye de Flaran (pp. 7-52). Toulousse: Presses Universitaires du Mirail.

Pallares, M. del C., \& Portela, E. (2007). El lugar de los campesinos. De repobladores a repoblados. En A. Rodríguez (Ed.), El lugar del campesino: en torno a la obra de Reyna Pastor (pp. 61-88). Valencia: PUV.

Pastor, R. (1980). Resistencias y luchas campesinas en la época del crecimiento y consolidación de la formación feudal. Madrid: Siglo XXI.

Pastor, R. (1999). Diferenciación, movilidad social y redes de relaciones en grupos intermedios inferiores. Comunidades campesinas y foreros en el Monasterio de Oseira, siglo XIII. En R. Pastor, I. Echegaray, A. Rodríguez López, \& P. Sanchez León (Eds.), Transacciones sin mercado: Instituciones propiedad y redes sociales en la Galicia monástica. 1200-1300 (pp. 193-243). Madrid: Consejo Superior de Investigaciones Científicas.

Pescador, C. (1961). La caballería popular en León y Castilla. Cuadernos de Historia de España, 33-34, 101-238.

Quirós Castillo, J. A. (2016). Inequality and social complexity in peasant societies. Some approaches to early medieval north-western Iberia. En J. A. Quirós Castillo (Ed.), Social complexity in early medieval rural communities. The north-western Iberia archaeological record (pp. 1-16). Oxford: Archaeopress Publishing.

Salrach, J. M. (1998). Les féodalités méridionales: des Alpes à la Galice. En J.-P. Poly \& E. Bournazel (Eds.), Les féodalités (pp. 313-388). París: Presses Universitaires de France.

Sánchez Albornoz, C. (1926). Estampas de la vida en León hace mil años. Madrid: Tipografía de la «Revista de Archivos».

Sánchez Albornoz, C. (1965). El precio de la vida en el reino asturleonés hace mil años. En Estudio sobre las instituciones medievales españolas (pp. 369-410). México: Universidad Autónoma de México.

Sánchez Albornoz, C. (1965). Las Behetrías. La encomendación en Asturias, León y Castilla. En Estudios sobre las Instituciones medievales españolas (pp. 9-183). México: Universidad Autónoma de México.

Sánchez Albornoz, C. (1973). España, un enigma histórico. Tomo II. Barcelona: EDHASA.

Sánchez Albornoz, C. (1978). El régimen de la tierra en el Reino Asturleonés hace mil años. Buenos Aires: Instituto de Historia de España, Universidad de Buenos Aires.

Sen, A. (1981). Poverty and Famines. An Essay on Entitlement and Deprivation. Oxford: Oxford University Press. 
White, S. (2003). Service for fiefs or fiefs for services. En G. Algazi, V. Groebner, \& B. Jussen (Eds.), Negotiating the Gift: Pre-Modern Figurations of Exchange (pp. 63-98). Göttingen: Vandenhoeck \& Ruprecht.

\section{Notas}

1 Se examinan las fuentes diplomáticas contenidas en las colecciones documentales de las instituciones eclesiásticas de la región: Sáez, Colección Documental del Archivo de la Catedral de León (775-1230). Vol. I (775-952) [en adelante CDACL I]; Sáez y Sáez, Colección Documental del Archivo de la Catedral de León (775- 1230). Vol. II (953-985) [en adelante CDACL II]; Ruiz Asencio, Colección Documental del Archivo de la Catedral de León (775- 1230). Vol. III (986-1031) [en adelante CDACL III] , Ruiz Asencio, Colección Documental del Archivo de la Catedral de León (7751230), Vol. IV (1032-1109), [en adelante CDACL IV]; Fernández Flórez y Herrero de la Fuente, Colección documental del monasterio de Santa María de Otero de las Dueñas I (854-1108) [en adelante CDOD]; Mínguez Fernández, Colección Diplomática del monasterio de Sahagún (Siglos IX y X) [en adelante, CDMS I]; Herrero de la Fuente, Colección diplomática del monasterio de Sahagún (857-1230), Vol. II (1000-1073) [en adelante CDMS II]; Ruiz Asencio y Ruiz Albi, Colección documental del monasterio de San Pedro de Eslonza, I, (912-1300) [en adelante CDSPE].

2 Tal es el caso de Menicio y Abola, que adquirieron en las primeras décadas del siglo X un huerto, una llosa, dos casas y por lo menos cinco tierras arables en Villa de Monna (CDACL I, doc. 9, año 894; doc. 13, año 898; doc. 14, año 899; doc. 25, año 910; doc. 32, año 914; doc. 26, año 911).

3 CDMS I, doc. 94, años 945-950. Donaciones a Sahagún: CDMS I, doc. 162, año 959; doc. 164, año 959.

4 CDMS I, doc. 188, año 961 y CDACL II, doc. 350, año [952-961] respectivamente. Otras transacciones en el mismo sentido: Eugenio y Creces recibieron del monasterio de Abellar un buey, un cobertor morisco y un colchón de lana como precio por sus tierras en Villobera (CDACL I, doc. 104, año 935), Venancio y Magino recibieron una "scala argentea", probablemente un plato o tazón de plata, por las tierras que vendieron al monasterio de Sahagún (CDMS I, doc. 55 , año 934) y lo mismo obtuvieron Félix y Froila por su heredad en Marialba de la Ribera (CDACL II, doc. 282, año 954), García obtuvo del monasterio de Sahagún un paño valorado en treinta sueldos, una piel de conejo de cinco sueldos y una silla de montar valorada en treinta sueldos por su parte en un monte en Cerecedo (CDMS I, doc. 139, año 953), Fortes recibió del mismo cenobio una yegua "rosella" con su silla y un buey negro valorado en dieciocho sueldos (CDMS I, doc. 291, año 977). Así también Vermudo obtuvo del monasterio de Ardón un cobertor morisco óptimo y un "parelium de saccos" (CDACL II, doc. 322, año 959), Regina recibió como precio por su heredad un conjunto de bienes valorados en cien sueldos que consistían en un lecho de lana o de tela, una piel de cordero, una prenda de vestir, zuecos y un plato o tazón de plata (CDACL II, doc. 434, año 974) y Vellite Adúlfiz obtuvo como precio por la cuarta parte de su heredad un caballo "rosello" que valía cien sueldos con su silla y su freno (CDACL III, doc. 638, año 1004).

5 Compras: adquieren en Villa de Meizara una dehesa, adquiriendo primero la mitad, divida a su vez en cuatro partes, y luego las dos cuartas partes restantes (CDACL II, doc. 372, doc. 373, doc. 374, año 964). En ese mismo año se documenta que Martín y Félix deben entregarles su parte en otra dehesa por los cereales, el grano y el queso que les debían: "Et accepimus de uos in pretio, pro ipsa deuesa, ipsa cibaria, et ipsum kaseum et ipsum uinum quod debuimus nos a tibi Arias" (CDACL II, doc. 371, año 964).

6 En el entorno de Valdoré, el presbítero Braulio adquirió una parte en ciertos árboles frutales por un cuartario de grano. En el mismo año también adquiere una tierra en Montecillo y la tercera parte de otra tierra en la Vega de Adriano por una oveja y una "rel[ia]" (CDOD, doc. 15, doc. 16, año 964). Posiblemente sea también el presbítero Braulio quien adquirió en 974 la mitad de una tierra en El Castro (CDOD, doc. 19, año 974). En un diploma fechado en el año 964 se refiere el préstamo a Gogina, quien debió entregarle la mitad en ciertos árboles frutales en Montecillo por el cereal que éste le había prestado: "et uindimus et dedimus uobis ipsos furctuarios in orem pro ipsa ceuaria quem mizi prestatit" (CDOD, doc. 14, año 964). Dada la coincidencia temporal y onomástica y el precio pagado por la adquisición de la otra mitad de los árboles frutales de Gogina, es esperable que la compra de junio de 964 (doc. 15) también refiriese un préstamo no satisfecho. El presbítero Gutier recibió una viña por las cinco heminas de renovo y los dos cuartarios de cereales que debía Citi: "Et accepimus de uos in precio eminas $V$ de uino, qui fuerunt de renouo, et II quartellas de ciuaria, et amatauimus tiui ipso renouo et dedisti nobis argenzos $V^{\prime \prime}$ (CDACL III, doc. 564, año 994).

7 Esto lo diferencia del crédito moderno en el que el dinero se presta como capital (Colombo, 2015).

8 En el diploma fechado en el año 989 se refiere al préstamo que habría hecho el monje Zuleimán de quince heminas de vino a Avita y sus hijos Cristóbal, Arias, Domingo, Scapa y Eugenia. Al cabo de seis años, con el lucro correspondiente la deuda había ascendido a treinta sueldos, por lo que le entregaron una viña y una tierra en Villa de Monna: "et fuerunt hodie annos VI cum suo locro et postea abuimus uobis a dare XXX solidos in conpagina. Et pro ipsos XXX solidos accepimus de uobis pro inde ipsa terra et ipsa uinea que iam supra diximus" (CDACL III, doc. 525, año 989). Otro diploma fechado 
en 1001 aprecia en cuarenta sueldos las seis heminas de vino y los tres modios de cereales de los que se apropió Arias (CDACL III, doc. 603, año 1001).

9 "et accepimus de uobis in precio solidos $X$, pro uino qui remansit super nos de renobo preciatum in X solidos" (CDOD, doc. 95, año 1014), "Et accepimus de uos in pretio, pro ipsa deuesa, ipsa cibaria, et ipsum kaseum et ipsum uinum quod debuimus nos a tibi Arias" (CDACL II, doc. 371, año 964), "Et uindimus et dedimus uobis ipsos furctuarios in orem pro ipsa ceuaria quem mizi prestatit" (CDOD, doc. 14, año 964), "pro illa cebaria de renobo que mici abuisti a dare, modio i maiore" (CDACL II, doc. 465, año 979).

10 Así podrían entenderse ventas como las que hizo Fredisilo de un herrenal por tres modios de cebada (CDACL I, doc. 228, año 950) o Patre de una tierra por una "capra et I quarto de cibaria" (CDMS I, doc. 138, año 952).

11 Jiménez Muñoz (2008) señala que la prohibición general de la usura en el derecho canónico antes de ser instaurada en el siglo XII fue apuntada en los concilios de Constanza (814), París (829) y Ticino (850) y normas particulares como el Capitular de Inocencio II de 789. Por su parte, Marlasca Rodríguez (2008, pp. 611-612) apunta que la Lex Visigothorum dedica una única disposición "De usurisfrugum" al problema de los préstamos en especie estableciendo que "quienquiera que prestase a otro frutos de la tierra, sólidos o líquidos, no recibiese más que la tercera parte”, la misma norma que recoge el Fuero Juzgo.

12 Se trata de la venta que hizo Mercadarius de una corte que tenía en la ciudad de León y que había adquirido "expeccunia mea de Miro Harraze, quem ad me acceperat ad usuram" (CDACL II, doc. 379, año 964). Recoge este documento Sánchez Albornoz (1926, p. 42, 1973, pp. 190-206) y en una prolongada asociación entre la minoría judía y el préstamo usurario atribuye este origen a Mercadarius

13 El vocablo "renovo" aparece en algunos documentos que no corresponderían a sectores aristocráticos CDMS II, doc. 499, año 1047; CDMS II, doc. 535, año 1049.

14 Monique Bourin (2007) ha señalado la importancia de los préstamos en los procesos de estratificación de las comunidades del Languedoc en los siglos XIII y XIV, un aspecto también señalado por Laurent Feller (2015) en su reciente trabajo de síntesis "Campesinos y señores en la Edad Media".

15 Quizás su papel destacado en la comunidad se refleje en la actuación como testigo de Taurello en una compra que hizo Menendo en el Valle de Ujo (CDACL II, doc. 310, año 959). Asimismo, en un diploma fechado en el año 960 se consigna que Taurello y Principia habían adquirido en Villa de Ujo la cuarta parte en una tierra y en unos árboles frutales así como la mitad de otra tierra pagando por estos bienes cereales y sidra, lo que tal vez estuviera encubriendo un préstamo no consignado como tal (CDACL II, doc. 324, año 960).

16 CDACL II, doc. 473, año 980. Al día siguiente de la confección de la citada donación se produjo una venta, mediante la cual dos de los hijos de Bonmenti, Bellito y Don Pater, vendieron sus partes en una tierra yerma junto al río Aller, en la villa de Ujo por la que recibió Bellito "porca media, in alio precio quartaria $V$ ” que debía dar por un pleito con Kalcano y Don Pater (CDACL II, doc. 474, año 980).

17 "et gubernas me et calentas mici et facis multum bonum" (CDACL II, doc. 357, año 962).

18 Una dinámica similar puede observarse en torno al presbítero Munio, probablemente vinculado a la catedral leonesa y que aparece en algunos documentos mencionado como "mayordomo" y "primicerio". Munio había adquirido algunas viñas en Villa de Montane y sus alrededores, en el territorio de Eslonza en la década de 970 (CDACL II, doc. 459, año 978; doc. 467, año 979; doc. 471, año 979). A la vez, prestó a Quostrildi y sus hijos cereales y vino de "renobo" (CDACL II, doc. 457, año 978 y doc. 465, año 979). A la vez, fue profiliado por Spanarico y Cota quienes le entregaron para después de su muerte la tercera parte de sus bienes porque les hacía bien y "modoras de omnes maculas" (CDACL III, doc. 455, año 978).

19 Es la situación que Amartya Sen, desde el enfoque de entitlement, nombra como el fracaso directo para obtener los alimentos necesarios (direct entitlement failure to food) y que es un fenómeno diferente e independiente de la disponibilidad total de alimentos en la región (Sen, 1981, pp. 154-166).

20 De los diecinueve diplomas que refieren préstamos en especie, al menos nueve corresponderían a viudas (CDOD, doc. 14, año 964, CDACL II, doc. 457, año 978; doc. 465, año 979, CDACL IV, doc. 1023, año 1045, CDMS II, doc. 499, año 1047; CDSPE, doc. 51, año 1084) u hombres o mujeres solos (CDACL III, doc. 564, año 994; CDMS III, doc. 820, año 1085; CDOD, doc. 262, año 1064).

21 CDMS I, doc. 133, año 951.

22 CDOD, doc. 56, año 1001 y doc. 99, año 1014 respectivamente.

23 CDACL II, doc. 463, año 979 y doc. 464, año 979.

24 Este planteo acuerda plenamente con las afirmaciones de Wendy Davies (2007, pp. 153-154) en su pormenorizado estudio de las donaciones en el norte ibérico altomedieval. Efectivamente, las donaciones revisadas no evidencian que los beneficiarios adquiriesen derechos y poder de mando sobre quienes efectuaban las donaciones ni obligaciones de servicios o un compromiso total e irreversible como supondría el modelo de la encomendación y de la profiliación de Abilio Barbero y Marcelo Vigil (1978, pp. 376-394) para quienes "el status de la persona queda rebajado y puede ser semejante a la de un siervo". 
25 La práctica del alboroque se observa en las referencias al pan y al vino entregado en las transacciones que era, probablemente, consumido entre los presentes. Un diploma castellano ofrece una clara imagen de esta práctica ya que afirma que los vendedores además del precio recibieron "pozale de bino in II argenzos que uiuimos cum nostras testimonias et testibus” Ruiz Asencio, Ruiz Albi y Herrero Jiménez, Los becerros gótico y galicano de Valpuesta, doc. 36, año [960-961]. En la introducción al volumen dedicado la celebración banquetes y los dones de comida en la Europa Medieval del Journal of Medieval History, A. J. Watson y Lars Kjær (2011) señalaban el banquete como una herramienta para representar y conceptualizar el status y las relaciones de solidaridad.

26 CDACL III, doc. 736, año 1015: se menciona "una viña que fue del monje Velasco y la perdió por el vino de renovo que no pudo devolver”; CDOD, doc. 236, año 1045; CDMS III, doc. 815, año 1084; CDMS III, doc. 820, año 1085.

27 Sectores no aristocráticos: CDOD, doc. 14, año 964, CDACL II, doc. 371, año 964; doc. 473, año 980; CDACL III, doc. 564, año 994. Magnate laico (Munio Flaínez): CDMS I, doc. 198, año 962. Institución eclesiástica: monasterio de Eslonza: CDSPE, doc. 24, año 950. Presbítero Munio (mayordomo y primicerio, vinculado a la catedral leonesa): CDACL II: doc. 457, año 978; doc. 465, año 979. Monje Zuleimán: CDACL III, doc. 525, año 989.

28 Entre el año 1000 y 1049 se encuentran nueve diplomas que dan cuenta de préstamos y solamente dos pueden ser asociados con sectores no aristocráticos, los dos préstamos del presbítero Pedro en Villalobos (CDMS II, doc. 499, año 1047 y doc. 535, año 1049) mientras que cinco pueden asociarse a magnates laicos (CDACL IV, doc. 1023, año 1045; CDOD, doc. 95, año 1014; doc. 192, año 1030; doc. 235, año 1044; doc. 236, año 1044) y otros dos a instituciones religiosas (CDACL III, doc. 736, año 1015, CDMS II, doc. 427, año 1030). Entre los años 1050 y 1099 se encuentran doce diplomas que refieren préstamos. Diez corresponden a magnates laicos (CDACL IV, doc. 1164, año 1069; CDMS II, doc. 725, año 1073; CDMS III, doc. 815, año 1084; doc. 820, año 1085; CDOD, doc. 262, año 1064; doc. 272, año 1069; doc. 286, año 1090, doc. 287, año 1090; CDSPE, doc. 51, año 1084; doc. 54, 1085) y uno a una institución eclesiástica (CDMS III, doc. 998, año 1097). El único que corresponde a un sector no aristocrático atañe al diácono Miguel, tenente de Santa María de Curueño: CDMS II, doc. 631, año 1063.

29 Elo parece recibir como prenda diversas prendas y objetos domésticos como una cama, un sábana de cama, objetos de mesa, fundas de colchón entre otros (CDACL IV, doc. 1184, año 1073). Vellite Eliániz era fiador de su hermana, quien huyó con un hombre casado por lo que Vellite debía entregar treinta sueldos de plata a la condesa doña Sancha, abadesa del monasterio de San Juan de Val de Ardón. No teniendo cómo pagar esos treinta suelos de plata, entregó su heredad en Ardón que estaba junto a la iglesia de San Cipriano y en Fresno de la Vega: "pro fidiatura que super nobis kadiuit ut pariasemus uobis illa; erant numero argenti pondo pensante XXX solidos, et non auuemus unde illo uobis conplere, et nostra expontanea uolumtate facimus uobis kartula de nostra ereditate ut posideatis uos et omnis posteritas uestra que plagauilem fuerit" (CDACL IV, doc. 1013, año 1044). Este Vellite Eliániz se trataría de la misma persona que aparece diez años antes junto con dos presbíteros, Juan y Domingo, donando una serie de bienes rurales al monasterio de San Juan Bautista y Santa María en la ciudad de León y entre los que se encuentran una "clausa" en el atrio de la iglesia de San Cipriano (CDACL III, doc. 865, año 1030).

30 Tomando los diplomas de las colecciones documentales de referencia, la participación en compras y permutas de quienes podrían ser identificados con estos sectores (advirtiendo siempre la provisionalidad de estos datos y un margen de duda razonable para su identificación) representaría alrededor del 14\% de los diplomas entre 1000-1024, el 10\%, entre 1025 y 1049 , el $8 \%$ entre 1050 y 1074 y el $5 \%$ entre 1075 y 1099 . El promedio del siglo, $9 \%$ se encuentra, no obstante, por debajo del $13 \%$ sobre el total de los diplomas del siglo X.

31 Así, por ejemplo, Abdella y su mujer y su cuñada debieron donar a Munio Fernández una heredad por haber incurrido en una relación sexual ilícita "Pro ipsa causa que fecit mala, pro inde damus ista hereditate ad integrum, montes, fontes, pasquis, paludibus, fructuarios uel infructuosas pro isto fornicio que fecit” (CDACL III, doc. 671, año 1008).

32 CDMS II, doc. 427, año 1030. Otros casos en el mismo sentido: Annaya Velaz pagó por Domingo Quintílaz un caballo pardo por el caballo que éste había robado (CDMS II, doc. 725, año 1073) y Pedro Flaínez paga por Vicenca y Lalino diez sueldos que debían pagar por haber golpeado a otra persona y haber cabalgado en la yegua del señor (CDACL IV, doc. 1164, año 1069).

33 CDMS III, doc. 861, año 1090.

34 CDACL IV, doc. 1106, año 1057.

$35 \mathrm{La}$ actuación de los boni homines en relación a los procesos judiciales aparece documentada en: CDACL III, doc. 838, año 1027; doc. 846, año 1028; doc. 851, año 1029; doc. 856, año 1029; CDACL IV, doc. 906, año 1032; doc. 912, año 1033, entre otros.

36 CDACL III, doc. 841, 1027. También en este sentido se encuentra la profiliación que hizo Domingo Lezéniz al conde Don Pelayo para "que abeam de uos prestamos et moderancia et que non abea malio domino nisi uso domnos meos" (CDACL III, doc. 854, 1029).

37 CDMS III, doc. 909, 1093.

38 Donaciones de bienes por parte de magnates laicos que obedecerían al "buen servicio": CDACL IV, doc. 1031, año [1016-1045]; CDMS II, doc. 365, año [952]; doc. 465, año 1042; doc. 606, año 1059; doc. 620, año 1062; doc. 638, 
año 1064; doc. 666, año 1068; doc. 676, año 1068; doc. 683, año 1069; doc. 715, año 1072; doc. 720, año 1073 ; doc. 721, año 1073; CDMS III, doc. 737, año 1074; doc. 752, año 1077; doc. 783, año 1080; doc. 860, año 1090; doc. 866, año 1090; doc. 873, año 1091; doc. 917, año 1094; doc. 952, año 1095; doc. 953, año 1095; doc. 983, año 1096; doc. 1028, año 1098; doc. 1088, año 1102, entre otros.

39 La donación de Tello Gutiérrez a Diego Pátrez; CDMS II, doc. 606, año 1059. La posterior donación al monasterio de Sahagún se encuentra en CDMS III, doc. 909, 1093.

40 "serbias mici in diebus meis cum illo" (doc. 636, año 1064). También en la donación que hicieron María Vermúdez y sus hijos a la sede leonesa se establece que conservarían la corte y otros bienes anexos durante su vida y hasta la generación de sus nietos prestando con esta servicio a la sede sin otro señor "et faciat ceruitium (sic) cum illa ad ipsa sede Sancta Maria sine alio domno" (CDACL IV, doc. 1214, año 1079).

41 Los extractos corresponden a: CDMS II, doc. 683, año 1069; doc. 715, año 1072 y doc. 365, [año 952] respectivamente. Expresiones similares pueden encontrase en: CDMS II, doc. 465, año 1042; doc. 606, año 1059; doc. 638, año 1064; doc. 666, año 1068; doc. 720, año 1073, doc. 721, año 1073; doc. 866, año 1090; doc. 873, año 1091; doc. 917, año 1094; doc. 952, año 1095; doc. 953, año 1095; doc. 983, año 1096; doc. 1028, año 1098.

42 Annaya Pérez y Arias Núñez entregaron caballos valorados en cien sueldos cada uno (CDACL IV, doc. 1051, año 1047 y doc. 1238, año 1085 respectivamente), Diego González entregó un caballo valorado en trescientos sueldos y un galgo "óptimo" (CDMS II, Doc. 465, año 1042), Velite Álvarez un caballo valorado en cincuenta sueldos, un galgo y un podenco y luego otro caballo bayo valorado en cien sueldos (CDMS II, doc. 638, año 1064; doc. 676, año 1068), Rodrigo Miguélez entregó dos caballos, uno de ellos "rucio" valorado en cien sueldos y un galgo (CDMS II, doc. 719, año 1073; doc. 720, año 1073 respectivamente), Pedro Cítiz entregó “in roborationem I potenco bono” (CDMS III, doc. 1028, año 1098).

43 CDMS II, doc. 465, año 1042.

44 CDMS II, doc. 721, año 1073.

45 Diego González aparece como confirmante de diplomas vinculados a la familia Alfonso (CDMS II, doc. 515, año 1048, doc. 516, año 1048; doc. 599, año 1058). Por su parte Pedro Cítiz aparece junto al conde Pedro Ansúrez (CDMS III, doc. 1096, año 1103).

46 Domingo Élaz entregó dos sillas, un "folle sardone", un paño “canzi” valorados en noventa sueldos (CDMS II, doc. 666, año 1068) y Pelayo Iohannez dio cincuenta sueldos de plata (CDMS II, doc. 715, año 1072). Fernando Ovéquiz entregó veinte sueldos de plata (CDMS III, doc. 752, año 1077). Si bien el sueldo de plata era en una moneda de cuenta y medida del valor de otros bienes, en estos casos podría asimilarse a las transacciones en metálico (amonedado o no) que Gautier Dalché (1997) encontraban en los "sueldo en plata”.

47 CDMS II, doc. 666, año 1068, se trataría de un paño QAFŞĪ, esto es, proveniente de Gafsa, Túnez: (García Arias, 2006, p. 196). Donación a Pelayo Antóniz: CDMS III, doc. 783, año 1080. Los azores que refieren los documentos aparecen asociados a la aristocracia : el rey Alfonso $\mathrm{V}$ recibe sendos azores como oferción en ocasión de una permuta de villas con Munio Muñoz (CDACL III, doc. 763, año 1019) y de una donación a Riquilo (CDACL III, doc. 788, año 1022). También el rey Fernando I recibía en confirmación de una donación al obispo de León un caballo morcillo y dos azores (CDMS II, doc. 505, año 1047). En la partida del Cid de Vivar se lamentaba al ver su casa "sin falcones e sin adtores mudados" (Cantar de Mio Cid. Edición, estudio y notas de Alberto Montaner, 2011).

48 Las recientes investigaciones arqueológicas muestran los límites del paradigma de una profunda división entre un mundo aristocrático ligado a los bienes de prestigio y un mundo campesino signado por la pobreza material. Tanto Christopher Loveluck (2009) como Florent Hautefeuille (2007) han señalado la existencia de asentamientos campesinos en los que aparecen signos de riqueza e integración con las redes de intercambio de larga distancia. En el ámbito del norte ibérico, Juan Antonio Quirós Castillo (2016) ha señalado las dificultades de una interpretación descontextualizada de la evidencia material puesto que el consumo no sólo expresa desigualdad sino que era una forma de construir identidades. 